\title{
Pathology of idiopathic megarectum and megacolon
}

\author{
J M Gattuso, M A Kamm, I C Talbot
}

\begin{abstract}
Background-The aetiology and pathology of both idiopathic megarectum and idiopathic megacolon are unknown. In particular, it is unknown whether there are abnormalities involving enteric nerves or smooth muscle.

Methods-Resected tissue was examined from 24 patients who underwent surgery for idiopathic megarectum, from six patients who had tissue resected for idiopathic megacolon, and 17 control patients who had surgery for non-obstructing large bowel cancer. Qualitative and quantitative histological examination was performed after staining with haematoxylin and eosin, periodic acid Schiff (PAS), Martius scarlet blue (MSB), and phosphotungstic acid haematoxylin (PTAH). Neural and glial tissue were examined after immunostaining with S100 and PGP9.5.

Results-Compared with controls, patients with idiopathic megarectum had significant thickening of their muscularis mucosae (median $78 v 33 \mu \mathrm{m}, \mathrm{p}<0.005$ ), circular muscle $(1000 v 633 \mu \mathrm{m}, \mathrm{p}<0.005)$, and longitudinal muscle (1083 $v 303 \mu \mathrm{m}$, p<0.005), despite rectal dilatation. This thickening was relatively greater in the longitudinal than in the circular muscle. Fibrosis of the longitudinal muscle was seen, using MSB staining, in $58 \%$, of circular muscle in $38 \%$, and of muscularis mucosae in $29 \%$ of patients. The relation between muscle thickening and fibrosis was variable. The density of neural tissue in the longitudinal muscle seemed to be reduced in patients with idiopathic megarectum. There was no thickening of enteric muscle or alteration in the density of innervation in patients with idiopathic megacolon.
\end{abstract}

Conclusion-There is notable thickening of the enteric smooth muscle in patients with idiopathic megarectum, but the architecture of the enteric innervation seems to be intact. Functional abnormalities of the latter remain a possible cause of the smooth muscle hypertrophy.

(Gut 1997; 41: 252-257)

Keywords: idiopathic megarectum; idiopathic megacolon

A number of different conditions cause large bowel dilatation in association with severe constipation, including Hirschsprung's disease, chronic idiopathic intestinal pseudo- obstruction, and idiopathic megarectum or megacolon. The last of these conditions affects both sexes, and symptoms may start in early or late childhood or in adulthood. Patients with idiopathic megarectum have a dilated rectum but the proximal colon is usually of normal diameter. The condition usually starts in childhood or adolescence, and faecal impaction is common. By contrast, patients with idiopathic megacolon usually do not experience impaction, and the symptoms often begin in adult life. The diagnosis of both these conditions is made on the characteristic clinical, physiological and radiological findings. ${ }^{12}$ Many patients can be managed successfully using long term laxatives, although some may require surgery. ${ }^{3}$

In contrast to the well defined histological abnormalities in Hirschsprung's disease and chronic primary intestinal pseudo-obstruction, the pathological basis underlying both idiopathic megarectum and idiopathic megacolon is unknown. In particular, it is unknown whether there are abnormalities involving the extrinsic nerves, the enteric nerve plexuses, or the intestinal smooth muscle. Abnormalities of any of these components could lead to gut dilatation and impaired motility.

Most reports on the pathology of these conditions relate to one or two patients only. The muscle layers have been reported as normal, ${ }^{7-13}$ atrophic $^{111415}$ and hypertrophic. ${ }^{911} 131416-19$ The intrinsic innervation has been reported as normal, ${ }^{7-12} 161920$ but decreased numbers of ganglion cells have also been reported. ${ }^{9}$ Most of these reports have included assessment by haematoxylin and eosin staining only, although silver staining has shown some neuronal abnormalities. ${ }^{11} 171821$

We have undertaken a detailed histological study of 30 patients with idiopathic megarectum or megacolon with the aim of identifying neural or smooth muscle abnormalities.

\section{Patients and Methods}

TISSUE STUDIED

Patients

Tissue was obtained from the colon or rectum, or both, of 30 patients (nine women, median age 24 (range 12-66) years) who had undergone surgery for idiopathic megarectum or megacolon. For the purposes of this study two groups of patients have been defined, based on the two different ways in which patients present clinically. The mode of clinical presentation bears a close relation to the extent of rectal dilatation. All patients with a megarectum, regardless of the proximal extent of the colonic dilatation, have been grouped together
Accepted for publication 10 March 1997 
as having "idiopathic megarectum". These patients all had a similar clinical presentation with faecal impaction. All patients with a normal diameter rectum but with colonic dilatation have been grouped together as having "idiopathic megacolon".

Twenty four patients had a megarectum, which was associated with a variable degree of proximal colonic dilatation: four patients had a dilated rectum only (all men, median age 21 (range 15-32) years), nine had a megarectum and a megasigmoid with a normal diameter proximal colon (two women, median age 18 (range 12-24) years, 11 patients had rectal and total colonic dilatation (four women, median age 27 (range $20-58$ ) years).

Six patients had a normal sized rectum with a dilated total colon (three women, median age 39 (range 34-66) years).

In all cases Hirschsprung's disease and other known causes of a dilated gut were excluded on the basis of either an intact rectoanal inhibitory reflex or a full thickness rectal biopsy specimen showing the presence of ganglion cells, prior to definitive surgery.

The following full thickness specimens were obtained: rectum from 16 patients, 15 of whom had a typical megarectum; sigmoid colon from 26 patients, all of whom had a megasigmoid; and more proximal colonic specimens from 18 patients, 16 of whom had a megacolon.

\section{Controls}

Control tissue was obtained from the resection specimens of 17 patients (six women, median age 58 (range 39-91) years) who had nonobstructing colonic or rectal cancer. None of these patients had any other known colonic pathology. The full thickness control specimens were taken at least $5 \mathrm{~cm}$ from the tumour and included rectum from 11 patients, sigmoid colon from 15, and more proximal colon from three.

Both in patients and controls all tissue included the taenia coli.

HISTOLOGICAL PREPARATION

Histology

Longitudinally orientated blocks of the full thickness of the bowel wall were fixed in $10 \%$ formol saline and embedded in paraffin wax. Sections were cut at $6 \mu \mathrm{m}$ and stained with haematoxylin and eosin, periodic acid Schiff (PAS), Martius scarlet blue (MSB), and phosphotungstic acid haematoxylin (PTAH).

\section{Immunohistochemistry}

Neural and glial tissues were immunostained with primary rabbit polyclonal antibodies raised against $S 100$ protein, a glial and Schwann cell marker, ${ }^{22}$ and protein gene product 9.5 (PGP 9,5) a nerve cell body and axon marker. $^{22} 23$

Sections from the same blocks used for routine histology were dewaxed in xylene and immersed in $0.3 \%$ hydrogen peroxide for 20 minutes to block any non-specific hydrogen peroxidase. Sections to be immunostained by S100 antibodies were incubated with $0.1 \%$ chymotrypsin for eight minutes at $37^{\circ} \mathrm{C}$. All sections were then incubated with the primary antibody (diluted 1 in 250: PGP 9.5, Ultraclone, Isle of Wight, UK, and S100, Dako, Copenhagen, Denmark) for one hour.

Sections were thoroughly washed with phosphate buffered saline (PBS), incubated with the second layer antibody (diluted 1 in 200: biotinylated affinity isolated swine immunoglobulins to rabbit immunoglobulins (Dako)) for one hour. The sections were washed with PBS and incubated for 45 minutes with the third layer, streptavidin (diluted 1 in 200: Streptavidin antibody, avidin biotin complex, Amersham International, Amersham, $\mathrm{UK})$.

After washing with PBS, the sections were "developed" with diaminobenzadine (DAB; Vector Laboratories, Peterborough, UK) with $0.03 \%$ hydrogen peroxide solution. The reaction was ended by washing in tap water and the sections were counterstained with haematoxylin and eosin.

\section{HISTOLOGICAL ANALYSIS}

On the haematoxylin and eosin stained sections, the presence of melanosis coli or other histological features was noted. On the same sections, the thickness of the muscularis mucosae and of the circular and longitudinal muscle of the muscularis externa was measured using a graded graticule. For each smooth muscle layer, three separate measurements were made across the section and the mean calculated. Inclusion bodies on the PAS stained sections and the presence of any fibrosis in the smooth muscle layers on the MSB and PTAH stained sections were recorded.

The density of S100 and PGP 9.5 immunoreactivity was assessed on a numeric scale of $0-5$ (absent to very dense) in the layers of the gut from luminal to serosal surface. The presence of the three divisions of the submucosal plexus - that is, Meissner's plexus, the intermediate plexus and Henle's plexus, ${ }^{24}$ was documented.

\section{STATISTICAL ANALYSIS}

Two-tailed Mann-Whitney U tests were carried out for statistical comparison between patients and controls for sections from the same colonic regions. Results from patients with idiopathic megarectum were analysed separately from those with idiopathic megacolon.

\section{Results}

Patients with idiopathic megacolon and a normal diameter rectum were older than patients with idiopathic megarectum (median (range) years, 39 (34-66) v $21(12-58), \mathrm{p}=0.002)$, in keeping with the clinical pattern of these two conditions. Patients with idiopathic megarectum who had distal gut dilatation only (that is, megarectum with or without a dilated sigmoid colon) were younger than those with megarectum and total colonic dilatation (18 (12-32) $v$ 27 (20-57), $\mathrm{p}=0.005)$. 

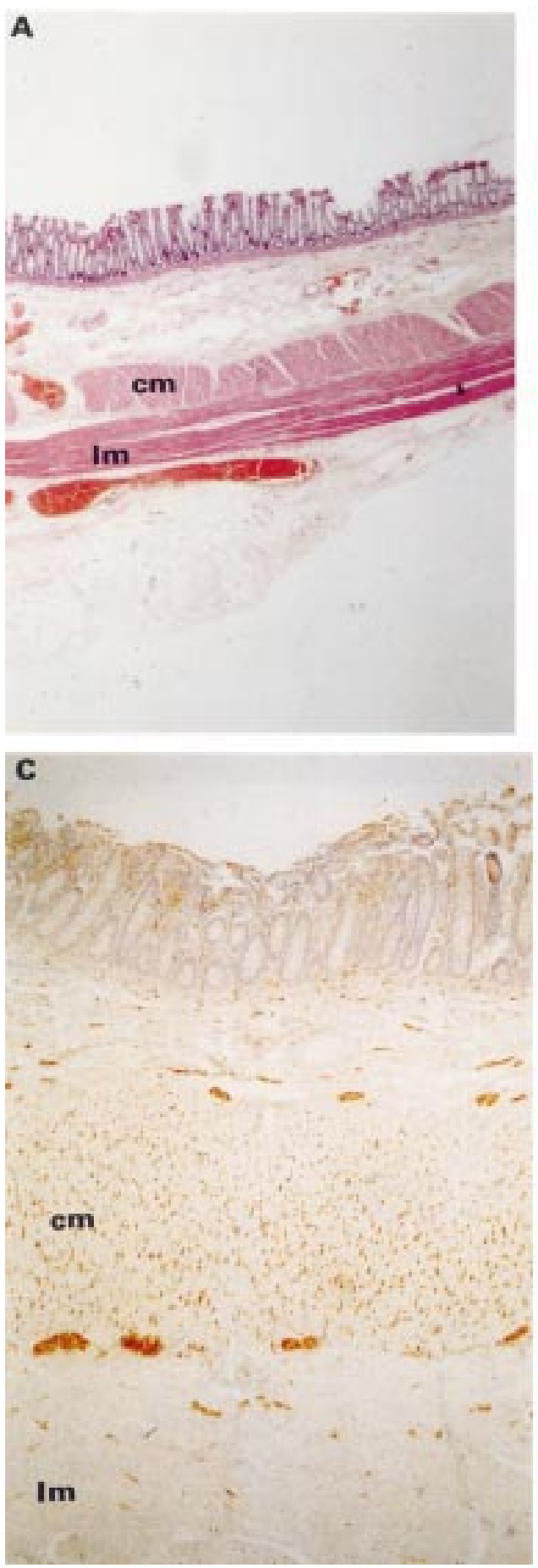
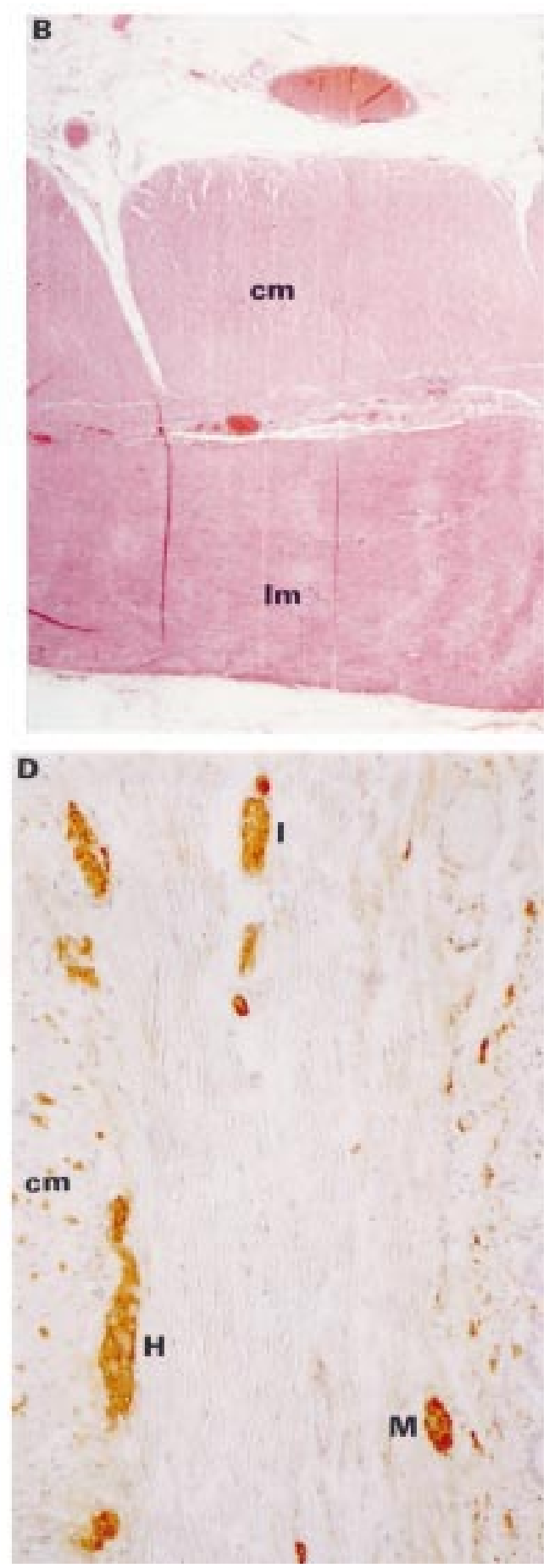

Figure 1: Haematoxylin and eosin stained sections of normal control tissue $(A)$ and tissue from a patient with idiopathic megarectum (B), taken at the same magnification (originally $\times 15$ ). Thickened muscularis externa can be seen in the patient with idiopathic megarectum. (C) and (D) PGP 9.5 immunoreactivity in rectal tissue of a patient with idiopathic megarectum. The dense staining in the circular muscle is in contrast to the sparse staining within the longitudinal muscle (C). The ganglia shown in (D) are from Henle's plexus (H), the intermediate plexus (I), and Meissner's plexus (M). $\mathrm{cm}=$ circular muscle; $l m$ = longitudinal muscle.

HISTOLOGY

Haematoxylin and eosin

Mild melanosis coli was seen in one $(6 \%)$ control, in eight $(33 \%)$ patients with idiopathic megarectum, and two (33\%) of six patients with idiopathic megacolon. Mild "obstructive colitis"-that is, a mild chronic inflammatory cell infiltrate in the lamina propria, was seen in one $(6 \%)$ control, $10(42 \%)$ patients with idiopathic megarectum, and three (50\%) patients with idiopathic megacolon. Hypertrophy of the muscularis externa (fig 1) was seen in eight patients with idiopathic megarectum, including one who had a thickened muscularis mucosae, and in two with idiopathic megacolon. Slight fibrosis of the muscularis externa was seen in one patient with idiopathic megarectum. 
TABLE 1 Thickness of the three smooth muscle layers, the muscularis mucosae, and the circular and longitudinal muscle of the muscularis externa in controls and patients with idiopathic megarectum and idiopathic megacolon (in $\mu \mathrm{m}$ )

\begin{tabular}{lccc}
\hline & Rectum & Sigmoid colon & Proximal colon \\
\hline Controls & 11 & 15 & 3 \\
$\quad$ Number & $33(21-61)$ & $25(17-48)$ & $21(15-30)$ \\
Muscularis mucosae & $633(333-1670)$ & $877(593-1667)$ & $360(167-700)$ \\
$\quad$ Circular muscle & $303(183-643)$ & $460(160-1092)$ & $250(45-808)$ \\
$\quad$ Longitudinal muscle & 21 & 21 & 10 \\
Idiopathic megarectum & $78(23-144) \dagger$ & $44(21-165) \dagger$ & $26(13-48)$ \\
$\quad$ Number & $1000(375-3410) \dagger$ & $801(287-3500)$ & $668(312-1592)^{\star}$ \\
Muscularis mucosae & $1083(233-3200) \dagger$ & $379(102-1643)$ & $233(150-1600)$ \\
Circular muscle & 1 & 5 & 6 \\
$\quad$ Longitudinal muscle & 73 & $41(15-57)$ & $29(23-53)$ \\
Idiopathic megacolon & 840 & $808(43-1178)$ & $479(393-1033)$ \\
$\quad$ Number & 570 & $357(90-727)$ & $403(145-767)$ \\
$\quad$ Muscularis mucosae & Circular muscle & &
\end{tabular}

Values given are the median (range) thickness. In all patients with idiopathic megarectum the gut dilatation extended for a variable extent proximally. The values given in this group are from dilated bowel only. In the proximal colon more than one colonic region was available in some patients (that is, ascending, transverse or descending colon). The three control patients provided five specimens; the 16 patients provided 30 specimens.

${ }^{\star} \mathrm{p}<0.05 ; \mathrm{tp}<0.005$.

TABLE 2 Ratio of circular to longitudinal muscle thickness in controls and in patients with idiopathic megarectum and idiopathic megacolon

\begin{tabular}{lllll}
\hline & Controls & & Idiopathic megarectum & Idiopathic megacolon \\
\hline Rectum & $2.28(1.36) \mathrm{n}=11$ & $1.44(0.96)^{\star} \mathrm{n}=21$ & $1.47 \mathrm{n}=1$ \\
Sigmoid colon & $2.41(1.14) \mathrm{n}=15$ & $2.17(0.97) \mathrm{n}=21$ & $2.63(1.12) \mathrm{n}=5$ \\
Proximal colon & $2.04(1.35) \mathrm{n}=3$ & $2.31(1.10) \mathrm{n}=10$ & $1.76(0.63) \mathrm{n}=6$ \\
\hline
\end{tabular}

Data are expressed as mean (SD).

All measurements from patients with idiopathic megarectum are taken from dilated segments of gut.

${ }^{\star} \mathrm{p}<0.05$

TABLE 3 Density of innervation in regions of the rectum in controls and in patients with idiopathic megarectum

\begin{tabular}{lllll}
\hline & $\begin{array}{l}\text { Longitudinal } \\
\text { muscle }\end{array}$ & Circular muscle & $\begin{array}{l}\text { Muscularis } \\
\text { mucosae }\end{array}$ & Lamina propria \\
\hline Controls & $1(0,2)$ & $4(4)$ & $2(0,2)$ & $2(0,3)$ \\
$\quad$ S100 & $2(1,2)$ & $4(4)$ & - & - \\
$\quad$ PGP 9.5 & $1(0,3)$ & $4(3,5)$ & $2(0,3)$ & $2(0,3)$ \\
$\begin{array}{l}\text { Idiopathic megarectum } \\
\text { S100 }\end{array}$ & $1(0,2)$ & $3(3,4)$ & $3(0,3)$ & $3(0,3)$ \\
PGP 9.5 & & & & \\
\hline
\end{tabular}

Values given are median (range) score. Scoring system: 0 , absent; 1 , very sparse; 2 , sparse; 3 , moderate; 4 , dense; 5 , very dense. Tissues from 11 control patients and 15 patients with idiopathic megarectum.

Dashes represent too much background staining for accurate scoring.

Mild diverticular disease, without any evidence of inflammation, was noted in one control.

Table 1 shows the diameters of the smooth muscle layers of patient and control rectum, sigmoid colon and proximal colon.

IDIOPATHIC MEGARECTUM

In patients with idiopathic megarectum the rectal muscularis mucosae and both the circular and longitudinal muscle of the muscularis externa were thickened. In dilated sigmoid colon the muscularis mucosae was abnormally thick, but the muscularis externa was within normal limits. All three smooth muscle layers were of normal thickness in dilated proximal colon.

IDIOPATHIC MEGACOLON

There was no thickening of any of the smooth muscle layers at any level in patients with idiopathic megacolon.

Table 2 shows the ratio of thicknesses of the circular to longitudinal muscle in the rectum, sigmoid colon and proximal colon in patients and controls. This shows that in the rectum of patients with an idiopathic megarectum there was proportionately significantly greater thickening of the longitudinal muscle compared with the circular muscle layer.

PERIODIC ACID SCHIFF

Inclusion bodies were not seen in tissue from either patients or controls.

MARTIUS SCARLET BLUE AND PHOSPHOTUNGSTIC ACID HAEMATOXYLIN

On MSB staining a slight increase in connective tissue in the muscularis externa of the sigmoid colon was seen in one control.

Idiopathic megarectum

MSB staining showed some fibrosis of the longitudinal muscle in 14 patients $(58 \%)$ with idiopathic megarectum. With MSB a similar increase in fibrosis was seen in the circular muscle of nine (38\%) patients and in the muscularis mucosae of seven (29\%).

Using PTAH staining an increase in fibrosis was seen in the longitudinal muscle in five $(21 \%)$ patients, in the circular muscle in four $(17 \%)$, and in the muscularis mucosae in one.

There was a variable relation between increased connective tissue within the smooth muscle layers (fibrosis) and increased thickness of smooth muscle. In patients with idiopathic megarectum fibrosis of the longitudinal muscle of the rectum was always associated with hypertrophy, but only about $50 \%$ of patients with a thickened longitudinal muscle had evidence of fibrosis. There was thickening of rectal muscularis mucosae in 13 patients with idiopathic megarectum but this was associated with fibrosis in only one.

Iidiopathic megacolon

Using MSB staining fibrosis of the longitudinal muscle was seen in two (33\%) patients, of the circular muscle in one, and in the muscularis mucosae in three $(50 \%)$.

PTAH staining showed some fibrosis in the muscularis mucosae in one patient and in the longitudinal muscle in another.

IMMUNOHISTOCHEMISTRY

Although reproducible staining was obtained within the muscularis externa and adjacent Henle's plexus, it was difficult to achieve the same quality of staining within the lamina propria, mainly because of excess of background staining.

Tables 3-5 show the density of innervation in different layers of the rectum, sigmoid and proximal colon. The density of neural tissue within the circular muscle was uniform across a section from the inner to the outer margins, but the density in the longitudinal muscle varied across a section in both controls and patients.

PGP 9.5 and S100 immunoreactivity of the circular muscle appeared normal. There seemed to be a decrease in the density of neural tissue of the longitudinal muscle in all the regions of the large bowel studied in patients with idiopathic megarectum (fig 1), although this reached statistical significance only in the sigmoid colon. 
TABLE 4 Density of innervation in regions of the sigmoid colon in controls and in patients with idiopathic megarectum and idiopathic megacolon

\begin{tabular}{|c|c|c|c|c|}
\hline & $\begin{array}{l}\text { Longitudinal } \\
\text { muscle }\end{array}$ & Circular muscle & $\begin{array}{l}\text { Muscularis } \\
\text { mucosae }\end{array}$ & Lamina propria \\
\hline \multicolumn{5}{|l|}{ Controls } \\
\hline S100 & $1(0-3)$ & $4 \quad(4)$ & $3(0-3)$ & $3(0-3)$ \\
\hline PGP 9.5 & $2(0-3)$ & $4 \quad(4)$ & $3(0,3)$ & $3(0,3)$ \\
\hline \multicolumn{5}{|c|}{ Idiopathic megarectum } \\
\hline S100 & $1(0-3)$ & $4 \quad(3-5)$ & $2(0-3)$ & $2(0-3)$ \\
\hline PGP 9.5 & $1(0-2)^{\star}$ & $4 \quad(3-5)$ & $3(0-3)$ & $3(0-3)$ \\
\hline \multicolumn{5}{|c|}{ Idiopathic megacolon } \\
\hline S100 & $1(0-2)^{\star}$ & $4 \quad(3-5)$ & $3(0-3)$ & $3(0-3)$ \\
\hline PGP 9.5 & $1(0-3)$ & $3.5(3-4)$ & $3(2-3)$ & $3(2-3)$ \\
\hline
\end{tabular}

Values given are median (range) score. Scoring system: 0 , absent; 1 , very sparse; 2 , sparse; 3, moderate; 4 , dense; 5 , very dense. Tissues from three control patients and patients with idiopathic megarectum and those with idiopathic megacolon, all of whom had a dilated proximal colon. ${ }^{\star} \mathrm{p}<0.05$.

TABLE 5 Density of innervation in regions of the proximal colon in controls and in patients with idiopathic megarectum and idiopathic megacolon

\begin{tabular}{|c|c|c|c|c|}
\hline & $\begin{array}{l}\text { Longitudinal } \\
\text { muscle }\end{array}$ & Circular muscle & $\begin{array}{l}\text { Muscularis } \\
\text { mucosae }\end{array}$ & Lamina propria \\
\hline \multicolumn{5}{|l|}{ Controls } \\
\hline S100 & $1 \quad(0-3)$ & $4(4)$ & $3(3)$ & $2(0-3)$ \\
\hline PGP 9.5 & $1.5(0-3)$ & $4(4)$ & $3(3)$ & $3(0-3)$ \\
\hline \multicolumn{5}{|c|}{ Idiopathic megarectum } \\
\hline S100 & $1 \quad(0-3)$ & $4(3-5)$ & $2(0,3)^{\star}$ & $3(0-3)$ \\
\hline PGP 9.5 & $1 \quad(0-2)$ & $4(3-4)$ & $2(0-3)$ & $3(0-3)$ \\
\hline \multicolumn{5}{|c|}{ Idiopathic megacolon } \\
\hline S100 & $1 \quad(0-3)$ & $4(3-4)$ & $2(0-3)^{\star}$ & $2(0-3)$ \\
\hline PGP 9.5 & $2(0-3)$ & $4(3-4)$ & $2(0-3)$ & $3(0-3)$ \\
\hline
\end{tabular}

Values given are median (range) score. Scoring system: 0 , absent; 1 , very sparse; 2 , sparse; 3 , moderate; 4 , dense; 5 , very dense. Tissues from three control patients and patients with idiopathic megarectum and those with idiopathic megacolon, all of whom had a dilated proximal colon. ${ }^{\star} \mathrm{p}<0.05$.

Henle's and Meissner's plexuses were identified in more than $95 \%$ of patients but the intermediate plexus was not seen in all patients (71-93\% varying with gut region), because of technical reasons rather than any intrinsic abnormality in patients. The observed ganglia were normal in appearance.

\section{Discussion}

The major finding in this study was thickening of the muscle layers of the gut in patients with a dilated large bowel. The notable thickening of the muscularis externa in the rectum involved both the circular and longitudinal muscle, hypertrophy of the latter being most noticeable. In patients with idiopathic megarectum atrophy of the smooth muscle layers of the gut was not seen, despite gut dilatation. The muscularis mucosae was also thickened.

A decrease in the density of innervation of the longitudinal muscle of the rectum was also seen. This change may relate to the hypertrophy of this smooth muscle layer or may be part of the primary pathological process. However, in the sigmoid colon of patients with idiopathic megarectum the decreased density of neural tissue within the longitudinal muscle was not associated with muscle hypertrophy, suggesting that this neural abnormality may be primary.

We found no clear association between muscle thickening and fibrosis. Patients with idiopathic megarectum with thickened muscularis propria or mucosae did not necessarily have associated smooth muscle fibrosis. Similarly, fibrosis of normal thickness enteric muscle was seen.

The architecture of the enteric nervous system appeared to be preserved in patients with idiopathic megarectum and idiopathic megacolon. No focal abnormality was found in either the myenteric or submucosal plexuses. The amount of neural tissue within the circular muscle was greater than that in the longitudinal muscle in both controls and patients, as has been reported previously in healthy subjects. ${ }^{26}$

Although the architecture of the enteric nervous system in patients with idiopathic megarectum and megacolon appeared to be intact, abnormalities of neurotransmission involving important inhibitory neurotransmitters, such as vasoactive intestinal polypeptide and nitric oxide, ${ }^{27-33}$ may have a role in the aetiopathogenesis of this condition.

In summary, we have shown that there is notable thickening of the enteric smooth muscle in patients with idiopathic megarectum. This does not seem to be associated with any noticeable abnormality of the architecture of the enteric innervation. However, functional abnormalities of the enteric innervation remain a possible cause for this smooth muscle hypertrophy.

We are grateful to Lloyd Soodeen and AM Abbasi for expert technical assistance.

1 Preston DM, Lennard-Jones JE, Thomas BM. Towards a radiologic definition of idiopathic megacolon. Gastrointest Radiol 1985; 10: 167-9.

2 Kamm MA. Investigation and management of megarectum and megacolon. Hospital Update 1993; 19: 280-8.

$3 \mathrm{Kamm}$ MA, Stabile G. Management of idiopathic megarectum and megacolon. Br ₹ Surg 1991; 78: 899-900.

4 Krishnamurthy S, Schuffler MD. Pathology of neuromuscular disorders of the small intestine and colon. Gastroenterology 1987; 93: 610-39.

5 Milla PJ, Smith VV. Aganglionosis, hypoganglionosis and hyperganglionosis: clinical presentation and histopathology. In: Kamm MA, Lennard-Jones JE, eds. Constipation. Petersfield: Wrightson Biomedical Publishing, 1994: 18392.

6 Smith VV, Lake BD. Pathology of intestinal pseudoobstruction. In: Kamm MA, Lennard-Jones JE, eds. Constipation. Petersfield: Wrightson Biomedical Publishing, 1994: 241-50.

7 Duhamel B. Histological investigations into "idiopathic megacolon". Arch Dis Child 1966; 41: 150-1.

8 Watkins GL. Operative treatment of acquired megacolon in adults. Arch Surg 1966; 93: 620-4.

9 Palmer JA, McBirnie JE. Atonic megacolon. Can f Surg 1967; 10: 15-20.

10 Nissan S, Bar-Maor JA. Further experience in the diagnosis and surgical treatment of short-segment Hirschsprung's disease and idiopathic megacolon. F Pediatr Surg 1971; 6: 738-41.

11 Barnes PRH, Lennard-Jones JE, Hawley PR, Todd IP. Hirschsprung's disease and idiopathic megacolon in adults and adolescents. Gut 1986; 27: 534-41.

12 Scott MJL. Idiopathic megacolon presenting with fatal inferior vena caval obstruction and colonic perforation. Acta Chir Scand 1988; 154: 605-7.

13 Stabile G, Kamm MA, Phillips RKS, Hawley PR, LennardJones JE. Partial colectomy and coloanal anastomosis for idiopathic megarectum and megacolon. Dis Colon Rectum 1992; 35: 158-62.

14 Kune GA. Megacolon in adults. Br f Surg 1966; 53: 199-205.

15 Morson BC, Dawson IMP, Day DW, Jass JR, Price AB, Williams GT (eds). Morson and Dawson's Gastrointestinal pathology. 3rd edn. Oxford: Blackwell Scientific Publications, 1990.

16 Roy AD. Resection of hindgut for idiopathic megacolon in adolescence. Br F Surg 1968; 55: 106-9.

17 Smith $\mathrm{B}$. The neuropathology of the alimentary tract. London: Edward Arnold, 1972: 65-7.

18 Smith B, Grace RH, Todd IP. Organic constipation in adults. Br F Surg 1977; 64: 313-4.

19 Stabile G, Kamm MA, Hawley PR, Lennard-Jones JE. Results of the Duhamel operation in the treatment of idiopathic megarectum and megacolon. Brf Surg 1991; 78: 661-3.

20 Stabile G, Kamm MA, Hawley PR, Lennard-Jones JE. Colectomy for idiopathic megarectum and megacolon. Gut 1991; 32: 1538-40.

21 Krishnamurthy S, Schuffler MD, Rohrmann CA, Pope CE. Severe idiopathic constipation is associated with a distinctive abnormality of the colonic myenteric plexus. Gastroenterology 1985; 88: 26-34. 
22 Lowe J. Immunohistochemistry in neuro-oncology. In: Felipe MI, Lake BD (eds) Histochemistry in pathology. Edinburgh: Churchill Livingstone, 1990: 77-97.

23 Wilson POG, Barber PC, Hamid QA, Power BF, Dhillon $\mathrm{AP}$, Rode J, et al. The immunolocalization of protein gene product 9.5 using rabbit polyclonal and mouse monoclonal antibodies. Br f Exp Pathol 1988; 69: 91-104.

24 Hoyle CHV, Burnstock G. Neuronal populations in the submucous plexus of the human colon. F Anat 1989; 166: $7-22$.

25 Crowe R, Kamm MA, Burnstock G, Lennard-Jones JE. Peptide-containing neurons in different regions of the submucous plexus of human sigmoid colon. Gastroenterology 1992; 102: 461-7.

26 Howard ER, Garrett JR, Kidd A. Constipation and congenital disorders of the myenteric plexus. F R Soc Med 1984; 77 (suppl 3): 13-9

27 Burleigh DE. N-Nitro-L-Arginine reduces nonadrenergic, noncholinergic relaxations of human gut. Gastroenterology 1992; 102: 679-83.

28 Huizinga JD, Tomlinson J, Pintin-Quezada J. Involvement of nitric oxide in nerve-mediated inhibition and action of vasoactive intestinal peptide in colonic smooth muscle. $\mathcal{F}$ Pharm Exp Ther 1992; 260: 803-8.

29 Stark ME, Szurszewski JH. Role of nitric oxide in gastrointestinal and hepatic function and disease. Gastroenterology 1992; 103: 1928-49.

30 Boeckxstaens GE, Pelckmans PA, Herman AG, Maercke YMV. Involvement of nitric oxide in the inhibitory innervation of the human isolated colon. Gastroenterology 1993; 104: 690-7.

31 Keef KD, Du C, Ward SM, McGregor B, Sanders KM. Enteric inhibitory neural regulation of human colonic circular muscle: role of nitric oxide. Gastroenterology 1993; 105: 1009-16.

32 O'Kelly T, Brading A, Mortensen N. Nerve mediated relaxation of the human internal anal sphincter: the role of nitric oxide. Gut 1993; 34: 689-93.

33 Koch TR, Schulte A, Telford GL, Otteron MF, Murad TM, Stryker SJ. Idiopathic acquired megacolon is associated with alteration of enteric nervous system products. Gastroenterology 1992; 102 (No. 4, Part 2): A469. 